\title{
The New Science of Dual Arithmetic Applied to Naval and Military Calculations
}

\section{Oliver Byrne Esq.}

To cite this article: Oliver Byrne Esq. (1866) The New Science of Dual Arithmetic Applied to Naval and Military Calculations, Royal United Services Institution. Journal, 10:38, 37-63, DOI: $10.1080 / 03071846609417196$

To link to this article: http://dx.doi.org/10.1080/03071846609417196

$$
\text { 册 Published online: } 11 \text { Sep } 2009 .
$$

Submit your article to this journal $\sqsubset x$

Џ Article views: 1

Q View related articles $\widetilde{2}$ 


\section{LECTURE,}

Friday, Ianutfy 19th, 1866.

Captax E. GaRDINER ,FISTMOtater R.N., C.B., in the Chair,

\section{THE NET SCIENCE OF DUAI ARITIIAETIC APPISIED TO NATAT AND MILITARY CALCULATIONS.}

By Onver Brnxe, Esq., formerly Professor of Mathenatics, Civil Engineers' College; Putney.

Gexthenex, $-\Lambda$ sciejutific lecture could only interest or entertain a highly enlightened and experienced andience like the greater portion of the one that I have the honour to address, either by bringing to their minds subjects long forgotten, or by offering materials for thonglit upon matters engaging their immediate attention; and but for the newness and importance of my subject, it would be my first dity to apologise for entering upon the principia of this or any scientific sub'ject, howerer profound.' 'Then, withont further introduction, nllow me to say that

Dual arithmetic is a new art of manourring numbers and inrestigating the relations' of quantities with ease and accurncy, with or without the use of tables. In the most general sense dunl aritlmetic is a new art, and not merely a new method of obtaining results that might be found by arts previonsly known. The science of dual arithmetic unfolds the capabilitios of numbers in an originnl manner, extends the boundaries of mathematical science, and establishles new rules, by which many difficult problems of the greatest titility and importanco are solved with ease, without the aid of tables, cumbersome formula, or methods of approximation previously resorted to.

The term dual is employed because the art has tuo branches, the bases of each branch being composed of two parts, but, chicfly because the digits of a dual number may be subjected to a variety of changes in'magnitude and position, while at the same time constantly equal in valne to two unchangeable extremes, namely, a natural number and a logarithm to a known base.

In combination the system is threcfold:-

$$
\text { Natural Number | Dual Number | Dunl Lognithm. }
$$

Since the digits of a dual number are susceptible of a vast variety of clanges without altering its two ultimate values, dual numbers may be said to be cliangealile without heing variahle. 
Numbers in the dual system of arithmetic are expressed by the continued product of the powrers of one or more of the bases which are seldom introduced into the figurative operations of the art. Irowercr; the powers and products are always obtainable by common addition and stabtraction.

$$
\begin{aligned}
& \text { I Bases of the ascenting branch. I } \\
& +\sim \ldots(10000+1) ;(1000+1) ;(100+1)(10+1) ;(1+1) ; \\
& \left(\frac{1}{10}+1\right) ;\left(\frac{1}{100}+1\right) ;\left(\frac{1}{1000}+1\right) ; \ldots \ldots 1 \text {; } \\
& \text { more conreniently witten } \\
& +\infty \ldots .10001 ; 1001 ; 101 ; 11 ; 2 ; 1.1 ; 1.01 ; 1.001 ; 1.0001 ; \ldots .1 \text {. } \\
& \text { increasing in magnitude from right to left. }
\end{aligned}
$$

These bases are less and less as they approach 1 , but cannot be leas than 1.

$$
\begin{gathered}
\uparrow \text { Bases of the descending bianch. } \uparrow \\
-\infty \ldots(1-10000) ; 1-1000) ;(1-100) ;(1-10) ;(1-1) ; \\
\quad\left(1-\frac{1}{10}\right) ;\left(1-\frac{1}{100}\right) ;\left(1-\frac{1}{1000}\right) ; \ldots . .1 ; \\
\text { but more correctly written } \\
-\infty \ldots-9990 ;-999 ;-99 ;-9 ; 0 ; .9 ; .99 ; .999 .1 .
\end{gathered}
$$

This scale of bases appronches 1 , but cannot be grenter than 1 .

A single example will make clear anything that mas seem too abstract in these gencral statements.

In order to aroid the common but faulty practice of illustrating. by small pet numbers, let us take the supposed diameter of the enrth through the poles, which is said to bo 7898.8809 statute niles of $5 \% 30^{\circ}$ feet each; therefore, the diameter $=41706091 \cdot 152$ feet, which, according to usage, is a contracted method of expressing

$$
\begin{gathered}
4 \times(10)^{7}+1 \times(10)^{6}+7 \times(10)^{5}+6 \times(10)^{3}+9 \times(10)^{1}+1+(10)^{-1} \\
+5(10)^{-3}+2(10)^{-3} .
\end{gathered}
$$

In conmon arithmetic the coeflicients $4,1,7$, sc., are termed digits, and do not exceed 9. In dual aritlmetic the porrers of the bases are only registered; they are also called digits, but they may vastly exceed 9. Thus $41706091 \cdot 152$ is equal to

$$
\begin{gathered}
\left(1-\cdot 1^{5}\right)^{3}\left(1-\cdot 1^{6}\right)^{2}\left(1-\cdot 1^{3}\right)^{3}\left(1-\cdot 1^{5}\right)^{8}\left(1-\cdot 1^{9}\right)^{9}\left(1-\cdot 1^{16}\right)^{1}(1+1)^{3} \\
\left(1+\cdot 1^{2}\right)^{1}\left(1+\cdot 1^{3}\right)^{2}
\end{gathered}
$$

when'multiplied by 10000000 . 
The bases being onitted, this dual number is written

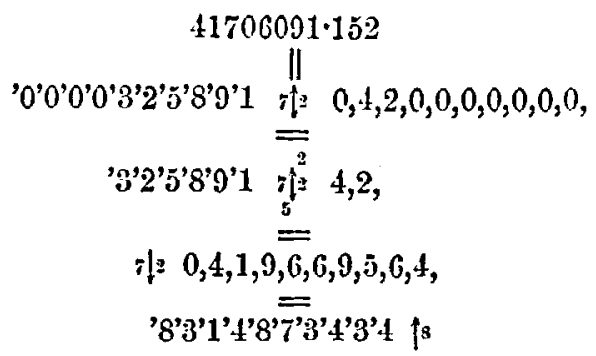

and equal to thousands of other dual numbers, each expressed by a different set of dual digits, but every one reducible to the same dunl logarithm 1754615775,.

In an extended form $41706091 \cdot 122$ is cqual to

'0'0'0'0'3'2'5's'9'1 $\uparrow(10)^{\gamma}(2)^{2} \downarrow 0,4,2,0,0,0,0,0,0,0$, moro conreniently' viritten

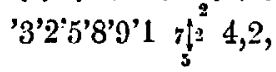

'3'2'5 \&c., are called dual digits, and express the porrers of the bases inrolved. The positions are reckoned from left to right before $\uparrow$ represent ing the descending branch, and from left to right after | representing the ascending branch. The powers of $1-1$ occupy the first position after ।; the powers 1.01, the sccond position after $l$, and so on. The powers of -9 the first position before $\uparrow$; the powers of -99 occupies the second position beforo 1 ; and so on. According to this conventional arrangement, ' 3 in the fiftl position before 1 represents $(\cdot 99999)^{3}, 0$, in the first position after $\mid$ indicates that no power $1 \cdot 1$ is involved, and in general ciphers are employed to indicate that no power of the corresponding bases are involred.

The position of a dual digit before, between, or after the signs $\uparrow$ and $\downarrow$ points out its raluc.

$$
{ }_{p}\{m=\quad m \mid n
$$

A small figure placed at $p$ designates the position occupied by a dual digit, and sometimes points out tho leading position occupied by the first of more dual digits than one. $m$ expresses $10^{n}$ and $n$ expresses $2^{n}$.

$$
m p
$$

The comma (,) is employed in the operations of dual arithmetic, while the period $(\cdot)$ is retained to separate whole numbers from decimal fractions. 


\title{
Geraral Fonurs of Dual Numbfrs or Fight Coxsecutive Digrts.
}

\author{
Ascending branch.$$
m \mid n \quad u_{1}, u_{3}, u_{3}, u_{4}, u_{5}, u_{\xi}, u_{F}, u_{3},
$$ \\ Deicending branch.$$
, v_{1}, v_{2}, v_{3}, v_{4}, v_{3}, v_{6}, v_{7}, v_{3} \times q_{m}
$$ \\ Both branches combined.

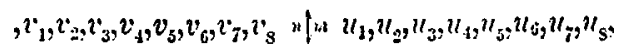

Nine dual digits give results true to nine places of figures. Ten dual digits give results true to ten places of figures, and so on.

$A$ dual mumber is easily transformed into another, all of whose digits being reduced to ciphers, except the last. The transformation of a dual number of eight cligits into another, whose first seven digits are ciphers, is termed redlicing a dual number to the eight position.

A dual number reduced to the eighth position is called a dual logarithin.

For example-

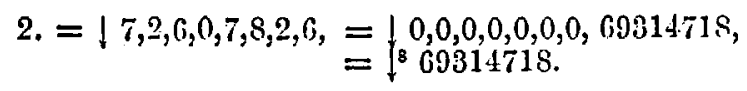

In practice the $S$ is omitted, and the expression is written

$$
2 .=\downarrow 69314718 \text {, which represents }(1 \cdot 00000001)^{\text {ro31/i1s. }} \text {. }
$$

Then 69314718 , is termed the dunl logarithm of $2 \cdot$ and written

$$
\downarrow,(2 \cdot)=69314718,
$$

The dual logarithm of 41706091.152 is iequal to the whole number 1754615775 , Dual logarithms are alrays whole numbers.

By very simple means the operator can find any two of the three corresponding numbers:-

\section{Natural number. | Dual number. | Dual logarithm.}

The remaining one being given. Indeed in all cases these reductions may be made by common addition and subtraction.

'Ihen, taking for granted that we can make such reductions when required, I now propose to illustrate the power of this new art hy applying it to solve some important practical problems, the solutioii of which would be either impossible, or so laborious, that no one would attempt to perform the operations by arts previonsly linown. 
Exayries.

Ex. 1. Find the 7 th root of the cube of $41706091 \cdot 152$.

$$
\begin{aligned}
& \downarrow
\end{aligned}
$$

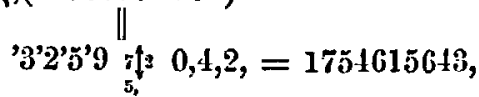

$$
\begin{aligned}
& \frac{1754015775}{7} \times 3=7551978189,=3 \mid 6,4,0,3,6,4,2,1, \\
& 3 \mid 6,4,0,3,6,4,2,1,=1844 \cdot 165 \text {. }
\end{aligned}
$$

Ex. 2. Required the common logarithm of $41706091 \cdot 152$ by a dircet calculation, or solve the equation

$$
\begin{aligned}
& 10^{r}=41706091 \cdot 152,
\end{aligned}
$$

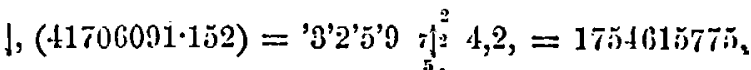

$$
\begin{aligned}
& \text { l. }(10)=: 1,2,3,2,6,7,8,2,0,={ }^{5} \text { '30258500, }
\end{aligned}
$$

J'hen by common division

$$
\frac{1754615775}{230258509}=7.62019919
$$

Ex. 3. Required the common nnmber answering to the common logarithm 7·62019919 by a direct calculation,

$$
\begin{aligned}
& 7 \cdot 62019949 \times 230258509=1754615775, \\
& 1754615775,=\text { ij }, 0,4,1,9,6,6,9,1,=\text { J }(41706091) . \\
& \therefore 762019949=\text { the common logarithm of } 41706091 .
\end{aligned}
$$

Ex. 4. Given $34 \cdot 56789 x^{5}-2845 \cdot 678 x^{4}-123 \cdot 4567 x^{3}+456 \cdot 7891 x^{2}$ $+56789 \cdot 12 x=-415978976.065$ to find a value of $x$, true to nino places of decimals.

In my work on the " $\mathrm{Art}$ and Science of Dual Arithmetic," it is shown that if $r_{1} u_{1}, u_{2}, u_{3}, \ldots$. be a root of the equation

$$
a x^{3}+b x^{4}+c x^{3}+a x^{3}+e x=f
$$

then $u_{1,} u_{s}, u_{3}$ may bo formed from

$$
u_{1}=\frac{f-f_{1}}{.+5 c r^{3}+4 b r^{3}+5 c r^{3}+2 e r^{2}+e r} .
$$

It requires but little observation to sec that a ralne of $x$ lies betreen 0 and 100, and on a closer inspection it will be found that a value lies between 10 and 30. $x$ may be found conveniently by putting any number. from 22 to 12 for $r ; 20$ is selected, because its square, cule, sc., are easily olitained and operated with. 
$a r_{6}=a_{1} \quad b r^{4}=b_{1} \quad c r^{3}=c_{1} \quad d r^{2}=r_{1} \quad e r=e_{1}$ $+11061724 \mathrm{~S}^{\cdot}-375308480 \cdot-987653 \cdot 6+182715 \cdot 64+1135782 \cdot 1$

+5505 times $+110 \ldots \ldots$

-15004 times -373

- 9503 times -

3 times
2 times
1 time
+ $\quad \cdots \cdots \cdots \cdots$

$-261 . \ldots \ldots \quad\left(f_{1}\right)$ take

$-415 \ldots \ldots . .(f)$ from

$-950)-151\left(+|1,=| u_{1}\right.$,

$a_{1}\left|5 u_{1},=a_{2} \quad b_{1},\right| 4 u_{1},=b_{3} \quad c_{1}\left|3 u_{1},=c_{2} \quad d_{1}\right| 2 u_{\mathrm{s}},=d_{2}$ $+178150185^{\circ}-549489146^{\circ}-1314566^{\circ} 942+221085 \cdot 924$

$$
e_{1} \mid u_{1},=e_{2}
$$

$+1249360 \cdot 64$

+89055 times

$1781 \ldots \ldots . .$.

-219764 times

5494

- $\quad 393$ times

$+\quad 42$ times

+121 time

13

$-\overrightarrow{1309)}$

2

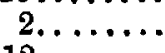

$-3712 . \ldots \ldots \ldots\left(f_{2}\right)$ take

$-4159 . \ldots \ldots$ (f) from

$-\overline{447} \ldots \ldots . . \quad\left(+10,3,=u_{n}\right.$,

$a_{2}\left|5 u_{2,}=a_{3} \quad b_{2}\right| 4 u_{3},=b_{3} \quad c_{2}\left|3 u_{3},=c_{3} \quad d_{2}\right| 2 u_{29}=l_{3} \quad e_{2} \mid u_{2},=e_{3}$ $+206826835 \cdot 619178123^{3}-1437722 \cdot 51+234687 \cdot 103^{3}+1287217 \cdot 52$

$$
\begin{aligned}
& +1034105 \text { times }+20682 \ldots \ldots \ldots \\
& -2476684 \text { times }-61917 . . . . . . \\
& \begin{array}{r}
-429 \\
+\quad 46 \text { times } \\
+
\end{array} \\
& +1281 \text { time }+128 \ldots \ldots . . \\
& \overline{144513)} \\
& -41227 . \ldots \ldots\left(f_{3}\right) \text { take } \\
& -41597 . . . \ldots . . .(f) \text { from }
\end{aligned}
$$

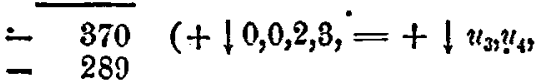

The root being thus far determined by contracted operations, let $20 \mid 1,3,2,5$, be substituted for $x$ in the given equation.

The succeeding operation by using the coefficients of the giren 
equation is independent of those before employed to determine $20 \downarrow 1,3,2,5$, . What follows not only determines $x$ to the required degreo of accuracy, but also corrects errors, if any be committed.

$$
\begin{aligned}
& 1,1,3,2,5,0,0,0,0,=12766017 \\
& \text { square }=25532034,=1,2,6,5,0,0,0,5,0, \\
& \text { cube }=38298051,=1,4,0,1,7,4,0,2,9 \text {, } \\
& 4 \text { th }=51064068,=1,5,3,4,2,4,0,7,9 \text {, } \\
& \text { 5th }=63830085,=0^{\prime} 5^{\prime} 4^{\prime} 5^{\prime} 9^{\prime} 2^{\prime} 6^{\prime} 3^{\prime}+2
\end{aligned}
$$

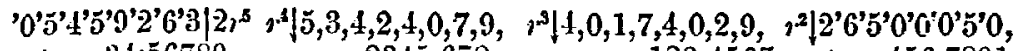

$$
\begin{aligned}
& +34.56789-2345.678-123.4567+456.7891 \\
& +209427346^{\circ}-625398452 \cdot-1448541.55+235863.66 \\
& r \nmid 1,3,2,5,0,0,0,0 \text {, } \\
& +\quad 56789 \cdot 12 \\
& +1290138 \cdot 27
\end{aligned}
$$

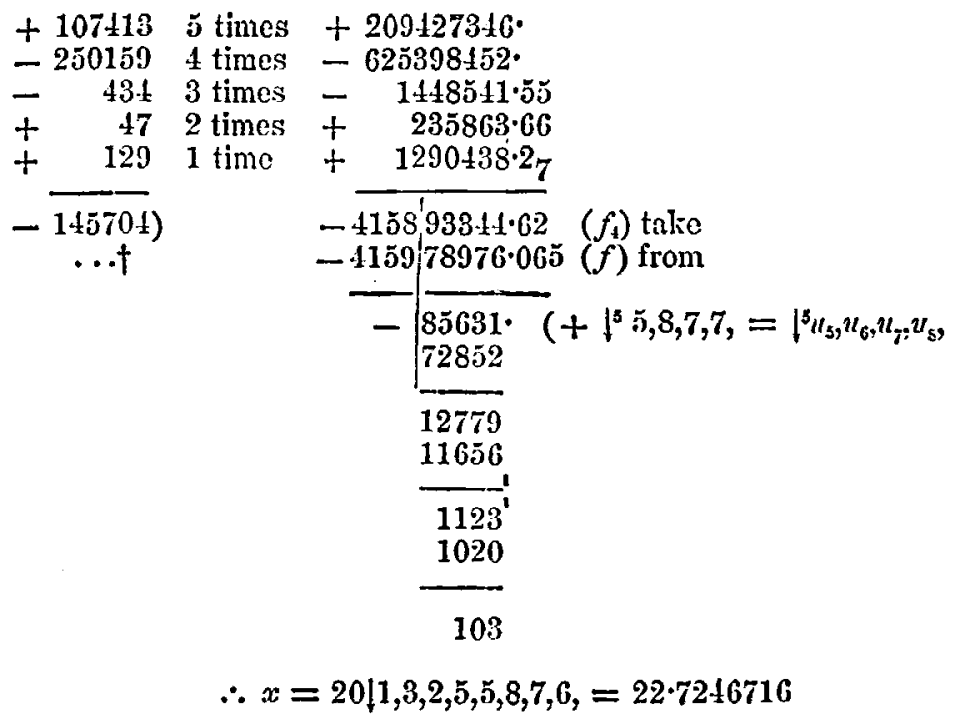

Common number. Dual number. Dual logarithm.

$$
x=22 \cdot 7246716\left\{\begin{array}{c}
22 \mid 0,3,2,5,5,8,7,5, \\
20 \mid 1,3,2,5,5,8,7,6, \\
15 \\
42,4,3,3,1,1,3,8, \\
12,6,6,9,8,4,4,7,
\end{array}\right\}=312345121,
$$

Ex. 5. Find the three sides of a right angled triangle that will havo one of its acute angles equal $21^{\circ} 19^{\prime} 37^{\prime \prime} \cdot 8$. 
'The length of an arc of $21^{\circ} 19^{\prime} 37^{\prime \prime} \cdot 8=\cdot 37222928$ radius $=1$.

In solving questions similar to this, the operative numbers

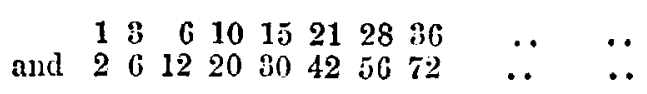

will be requircl, as well as the use of the following best. (Sce "The Young Dual Aritbmetician," pl. I16, 117.)

\section{RuLe I.}

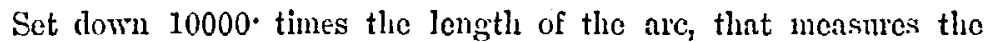
least of the acute angles, and divide it by the square root of 2 . The quotient will be the dual logarithm of the liypothenuse.

\section{KuLE II.}

Let $h$ represent the dual logarithm of the liypothenuse, and from the square of $h$ take $h$; then $l^{2}-3 h+2 ; h^{2}-5 h+6 ; h^{2}-7 h+12$; \&c., are found by merely subtracting 27 and adding at ench step a term of the series $201220 \ldots$

In what follows $\left[h^{2}-h\right]$ is put for $l^{2}-h$, disided by $10^{8}$; and so on.

$\left[h^{2}-3 h+2\right]$ is put for $h^{2}-3 h+-$, divided by $10^{8}$;

Put $A=$ the length of the arc to radius 1 , and $B=\left[12^{2}-\cdot \pi\right]$; $\mathrm{C}=\left[h^{2}-3 h+2\right] ; \mathrm{D}=\frac{\mathrm{B}}{\mathrm{G}}\left[h^{2}-5 h+6\right] ; \mathrm{E}=\frac{\mathrm{C}}{10}\left[h^{2}-7 h+12\right] ;$ $\mathrm{F}=\frac{\mathrm{D}}{15}\left[h^{3}-9 h+20\right] ; \mathrm{dec}$

Then $A-\mathrm{C}+\mathrm{E}-\mathrm{G}+\mathrm{I}-\mathrm{dce}$, gires the base, and $\mathrm{I}-13+\mathrm{D}-\mathrm{F}+\mathrm{II}-$ de., gires the perpendicular.

These rules are demonstrated in the anthases mork on the scionce of dual aritlmetic applied to trigonometry.

$$
\begin{aligned}
& \text { l, (.37222928) } \\
& { }^{\prime} 3 \prime\left|\frac{1}{2}\right|, 0,2,1 ; 0,8,3,3,0={ }^{\prime} 98824528 \\
& 1,(2 .) \\
& ={ }^{\prime} 34657359 \\
& 2 \\
& \overline{133481887}=1,(-2632068) \\
& \overrightarrow{20696877 t}=1,(\cdot 00927732) \\
& \therefore l,(h)=2632 \cdot 058 \quad l,\left(l^{2}\right)=6927732 \text {. } \\
& \text { But } \downarrow,(1 \cdot 00002632)=2632 \text {, } \\
& \therefore \text { Mypothenuse }=1 \cdot 00002632
\end{aligned}
$$


AH'HLED TO NAVAL AND MLLITAK CALUULATIONS.

$$
\begin{aligned}
& l^{2}=6927732 \\
& k=2632 \text {. } \\
& 6925100 \cdot=l^{2}-l \\
& 526.1 \\
& 6010836=h^{2}-3 h \\
& 5264^{\circ} \\
& \text { 6914572 }=h^{2}-5 h \\
& \text { \&c. dic. }
\end{aligned}
$$

Radius $=1 \cdot 00000000+$

$$
\begin{aligned}
& \Lambda=-37222928+ \\
& \mathrm{B}=-06925100-\left[l^{2}-h\right] \\
& \mathbf{C}=898589-\left[h^{2}-3 / \iota+2\right] \frac{1}{3} \\
& \mathrm{I}=\quad 79808+\left[\iota^{2}-5 / \iota+6\right] \frac{13}{6} \\
& \mathrm{E}=5980+\left[h^{2}-7 h+12\right] \frac{\mathrm{C}}{10} \\
& \mathrm{~F}=\quad 376-\left[h^{2}-9 h+20\right] \frac{\mathrm{D}}{15} \\
& \mathrm{G}=\quad 19-\left[l^{2}-11 h+30\right] \frac{\mathrm{E}}{21} \\
& \underline{I I}=\quad 1+\left[l^{2}-13 h+42\right] \frac{\mathrm{I}}{28}
\end{aligned}
$$

Perpenulicular.

$$
\text { Diasc }
$$

$$
\begin{aligned}
& \Lambda \quad 37222928 \text { Radius } 100000000+ \\
& \text { C } \overline{1} 141411 \text { ar. co. B } \overline{1} 3074900 \text { ar. co. }
\end{aligned}
$$$$
\text { II } \quad 5930 \quad 1) \quad 79808+
$$

G

$$
\begin{aligned}
& .36370250 \\
& \text { II } \\
& 16 \% \text { ar. co. } \\
& \text {-93154342 }
\end{aligned}
$$

$\therefore$ Natural sine of $21^{\circ} 19^{\prime} 37^{\prime \prime} \cdot 8=\frac{.36370250}{1 \cdot 00002032}=\cdot 36369293$

Ex. 6. hequired the log. sine, log. cosine, log. tangent, log. cutallgent, log. secant and log. cosecant of

$$
\begin{aligned}
& 21^{\circ} 19^{\prime} 37^{\prime \prime} \cdot 8
\end{aligned}
$$

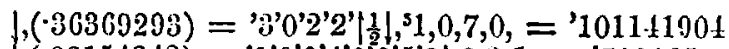

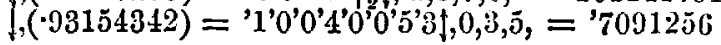

$$
\begin{aligned}
& \text { '101141904. } \\
& \text { h } \\
& \text { '2632, } \\
& \text { '1011+1901 } \\
& \text { 7091256, } \\
& \text { '1011.4536 }=\log \text {. sinc } \\
& \text { '94050648 }=\text {.log. tangeut. }
\end{aligned}
$$




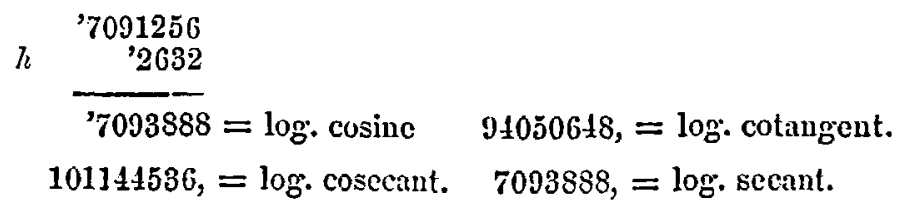

Ex. 7. Given the equatorial semidiameter of the earth = unity, and the polar semidiameter $=r=\frac{304}{305}$. Required $l$, the latitude of the central zenith, $l^{\prime}=32^{\circ} 29^{\prime} 46^{\prime \prime}$, the latitude of the apparent zenith, or the spheroidal or geographical latitude being giren.

Required also the radius of the place of observation and its logarithm.

$$
\text { Put } \rho=\text { radius of place of olsserration. }
$$

\section{lives.}

'lake $\frac{1}{3}$ of twice the sine of double either latitude, multiply by 1000 . and the dual number $\downarrow 0,1,6,0,1,0,2,0$, the result gives the seconds to be added or substracted.

$$
\begin{gathered}
r=\sqrt{\frac{\cos l^{\prime}}{\cos l \cos \left(l^{\prime}-l\right)}} \\
\therefore l,(\rho)=\frac{1}{2}\left\{1, \frac{\cos l^{\prime}}{\cos l}-\sqrt{1},\left(\cos \left(l^{\prime}-l\right)\right\}\right.
\end{gathered}
$$

$\operatorname{Sin} 2 l^{\prime}=\cdot 9062504$

$$
\begin{aligned}
& \frac{3}{3 \longdiv { 1 \cdot 8 1 2 5 0 0 8 }} \quad \downarrow 0,1,6,0,1,0,2,0, \\
& |6.0 .41| 7 \\
& 61020816 \\
& l^{\prime}-l=10^{\prime} 14=\frac{3661 \mid 2}{614^{\prime \prime}} \quad \because \cdot l=32^{\circ} 19^{\prime} 32^{\prime \prime} \\
& \cos \left(l^{\prime}-l\right)=\cdot 99999560 \\
& \therefore \downarrow l,(\cos (l-l))=\quad \cdot 410
\end{aligned}
$$

$\cos l=.84502350$

$\cos l^{\prime}=\overline{8+3162800}$

$1] 68686$

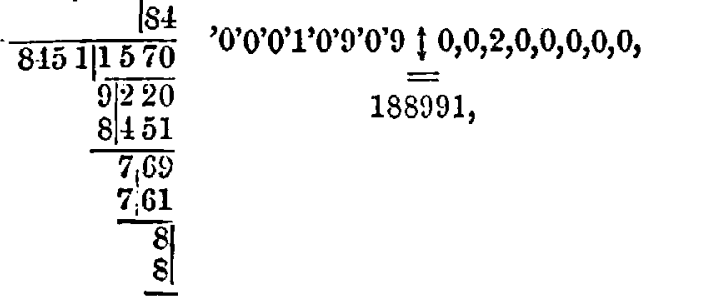




$$
\begin{aligned}
& \text { '188991 } \\
& \left.\frac{\cos l^{\prime}}{\cos l}-\downarrow, \cos \left(l^{\prime}-l\right)\right]=\frac{2 \frac{440,}{188551}}{\downarrow^{\prime} 94276}=\downarrow,(\rho) \\
& \frac{94276^{\circ}}{230208509}=\cdot 0004095 \\
& \text { Ar. co. }=9.9995905=\text { the common } \log \text { of } \rho \text {. } \\
& \downarrow,(\rho)={ }^{\prime} 94276={ }^{\prime}{ }_{3}^{5}, 5,7,7,4,=\downarrow,(\cdot 99905768) \\
& \because \rho=\cdot 99905768 \text {. }
\end{aligned}
$$

Ex. 8. Given the apparent altitude of the moon's centre $8^{\circ} 26^{\prime} 13^{\prime \prime}(a)$ the true altitude $9^{\circ} 20^{\prime} 45^{\prime \prime}(\Lambda)$, the apparent altitude of a star $35^{\circ} 40^{\prime}$ $\left(a_{1}\right)$, the true altitude $35^{\circ} 38^{\prime} 49^{\prime \prime}\left(A_{1}\right)$, and the apparent distance $31^{\circ}$ $13^{\prime} 26^{\prime \prime}(d)$; required the true distance (D), so as to find the longitude at sea.

It is well known that

$$
\begin{aligned}
& \operatorname{Cos} D=\left[\cos a+\cos \left(a+a_{1}\right)\right] \frac{\cos A \cos A_{1}}{\cos a \cos a_{1}}-\cos \left(A+A_{1}\right) \\
& \cos d=\cdot 8551482 \quad \cos A=\cdot 9867261 \quad \cos \Lambda_{1}=\cdot 8126236 \\
& \cos \left(a+a_{1}\right)=\cdot 7180824 \quad \cos a=\cdot 9891779 \quad \cos a_{1}=\cdot 8124220 \\
& \overline{1.5732306} \\
& \cos \left(A+A_{1}\right)=\cdot 7071950 \\
& \cos D=[1 \cdot 5732306] \frac{\cdot 9867261}{.9891779} \times \frac{.8126236}{.8124229}-\cdot 7071950
\end{aligned}
$$

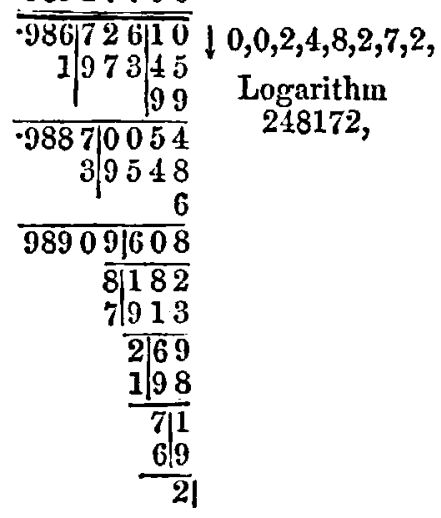




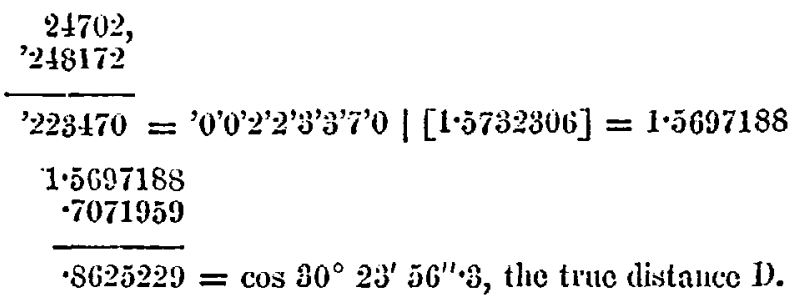

'I'his number, $41706091 \cdot 1$ ó2 Ex. 1 is generally witten, scientifically' spraking; in the form-

$\begin{aligned} & 1 \times(10)^{7}+1 \times(10)^{6}+7 \times(10)^{3}+6 \times(10)^{3}+9 \times(10)^{1}+1+ \\ & 10^{-1}+5 \times(10)^{-2}+2 \times(10)^{-3} .\end{aligned}$

I never question the conrentional contraction of that great number to $41706091 \cdot 152$. Observe, I omit the fourth and also the second power of (10). In all cases with common arithmetic the power of the base, and also the basc, are unrecorded. We merely set down the coefficient, its position before or after the decinal point marks its. value. It is readily shown that the dual system of notation is not as compound as the common system.

This system possesses a series of bases, although not employed more frequently than in the old systen. I only employ my bases necessary to show what they are.

I will begin with $+v$ and 'go on to $(10,000+1):(1,000+1)$ : $(100+1):(10+1):(1+1)$. One of these numbers decrensed onetenth; the other remaining stationary, which is 1 -. Procceding to $\left(\frac{1}{10}+1\right)$, and so on, until it approaches unity, but nerer becomes so small. These are more conveniently written by the second line.

$$
+\infty \ldots . .10001 ; 1001 ; 101 ; 11 ; 2 ; 1 \cdot 1
$$

Observe 2 is one of my bases $\ldots 1+1$. It would not appear to be so at first view.

'This is called the ascending branch, the bases of the ascending" lranch being positive, and the $\downarrow$ pointing towards a greater number. A comma, and an arrow $\downarrow$ are the only two signs I employ to do all my work, In this place I do not use auy other immovation in mathematics.

'The other base commences with $-\infty$; and goes on $(1-10000)$; $(1-1000) ;(1-100) ;(1-10) ;(1-1) ;\left(1-\frac{1}{10}\right) ;\left(1-\frac{1}{10}\right)$; $\left(1-\frac{1}{10}, 0\right) ; \ldots 1$.

Obscrve, 0 is a base of my system, because the bases may be written thus :-

$-\sim \ldots .-9999 ;-999 ;-99 ;-9 ; 0 ; \cdot 9 ; .99 ; .999 ; . .1$

It mity approach 1, but never arrive to be as great. 'The old tuise, 
10, has no such power of introducing 0 between positive and negative numbers. Therefore is deficient in range.

'The nurow points up $\uparrow$ in the clescencling branch, downwards in the ascending 1 . The powers of 10 and 2 are placed at the centre of the shaft. $n$ is the porrer of 10 , while $m$ is the porrer of $2 . p$ stands for position.

When ten digits are used the results aro true to ten places of figures; when twenty digits are used the results are true to twenty places of figures; when one hundred digit's are used the results are three hundred places of figures. The accuracy can be carried as far as you please.

With reference to Example 1, page 38, that is no power of 11 ; that is in the first position. There is the fourth power of 101 , and the square of 1001 in tho third position.

The first base. Wo will say wo count from $1+1$. There is $1+10$, first, second, and third, and so on. Powers of 1.1 in the first position, poweis of 1.01 in the second position, powers of 1.001 in the third position.

So that the position of the digit shows the base that is raised to the power, and the powers are only employed in these cases, not the coefhicients as in a common number. In a common number they use the coefficient and not the power of the base. In my system I use the indice only. It is the continued product of the powers of the base that forms the dual number, and not the sum. The dual number may assume a thousand difierent forms, bat it has two nltimate values, the dual logarithm on one side, and the naturnl mumber on the other :-

Natural number (dual number) dual logarithm. These two extremo values nerer change. What I hare termed a dual logarithm is a logarithm that is ten times more accurate than one taken from a table of seren figure logarithms. I have, therefore, used eight positions.

'This is another form of the same number :-'8'3'1'4's'7' 3 '4' 3 '4 $\mid 8$. (See Ex. p. 39).

That is the eighth power of 10 . Before the above arrow the comting begins, and after this the digits, ' 8 ' 3 ' 1 ' 4 , \&c.

The eighth power of 9 , the cube of 99 , the first power of 999 , the fourth power of 9999 , and so onl.

These are the -descending numbers. Yet very different from the dual number previonsly mentioned, yet amounting to the same common number, and to the same dual logatithm. 'The following is another form of the same dual number, all positive, all on the right of the arrow (Scc Ex. p. 39):-

$$
1 \mid 20,4,1,9,6,6,9,5,6,4
$$

The serenth power of 10 , the square of 2 , no power of 11 , the fourth power of 1.01 , the first power of 1.001 , so the position of the digits tells the power of the base. It must be again observed, I nerer use the bases in figurative operations.

This number is called a deal number because the base is composed of two parts; it has two ultimete values that never change. But as a

vor. $x$. 
whole it is threcfold, because the dual number is flexible, capable of an infinite variety of forms, and has two ralues.

If logarithms have to be used, a boy can make them himself. And ho can do more than that; he can tell whether Mr. Babbage's logarithms are right or nrong, or Mr. Taylor's, or Mrr. Brigg's. I hare supplied large tables, which can be looked at when the lecture is orer, of dual logarithms for the use of business men, sailors, and those who hare to make calculations, but who do not wish to make such calculations for themselres. But there is this difference between the ordinary tables, that any man can tell whether they are right or whether they are wrong. He can check them in fifteen minutes, and can tell whether a dual logarithm, or a dual number, or a sine, cosine, or secant, or anything else, is right or wrong, and in order.

But if this system did nothing more than calculate logarithms, it would be a very useless thing, indeed.

I want to cube that number, $41706091 \cdot 152$, and I want to take the seventh root of the cube. I at once find the dual logarithm of that number; first, the dual number, then the dual logaritlim. I multiply the dual logarithm by 3 , and divide it by 7 , and reduce it back again to its dual number, and then back again to the common number. So that I can take the cube of a number, the serenth root of that, or raise it tc iny porrer.

My first example in this syopsis is, how to extract tho serenth root of a number, the first problem on pago 41 .

Find the serenth root of the cubo of $41706091 \cdot 152$.

$$
\begin{aligned}
& \downarrow,(41706091 \cdot 12)=1754615643, \\
& \frac{1754615643, \times 7}{3}=7551978189, \\
& =\downarrow,(1844,165 j \text { tho root required. }
\end{aligned}
$$

I require to calculate in a direct way the logarithm of that number, boing the second example, or to solve the equation $10^{x}=41706091 \cdot 152$ (see Ex. 2, page 41).

Now, in this solution, I do not ber tho question. I do not get any number before or behind; I reduce it to a dual number at once, and then to a dual logarithm, I divide that by the dual logarithm of 10 , which I also find, The quotient is the common logarithm, by common division.

So that you can take up any number sou like, calculate the logarithm from the number itself. This problem was impossible before I discorered dual arithmetic; with the formula generally giren for the purpose, it was necessary to dodgo from 1 up, and then, by a series of differences, interpolate, either by machinery or other means, the intermediate numbers.

In the third problem, I wish to find tho number corresponding to tho logarithm. There is no formula to do it, and no one has ever attempted to givo one that I am acquainted with. It is rery casily done by the dual method, because wo hare nothing to do but to take the common 
logarithm, and multiply it by the dual logarithm of 10 , which gives tho dual number; bring it to a common number, and the required valuo is found.

We can test any common logarithm at once, and see whether the logarithm be correct or not. Eren the first number given in Baron Von Vega's system of logarithms, the logarithm of the mean distance of the earth from the sun is wrong. For that alone, dual arithmetic requires some little commendation.

In the higher branches of mathematics, its valuo is shown in such, as finding the area of the curve of probabilities between certain ordinates, and the roots of large equations. The fourth example is an example of the fifth power of the equation, in which the unknown quantity is erolred with rery largo coeflicients. This is tho general expression for the fifth power of an equation:-

(See page 41.)

$$
u,=\frac{f-f,}{f 5 \mathrm{ar}^{5} T^{4}+\mathrm{bp}+3 \mathrm{cr}+2 \mathrm{dr} r^{2} \downarrow \mathrm{er}}
$$

The first dual digit must always be equal to that. The denominator of that frnction is something like tho differential of tho equation, because you can see the powers $5,4,3,2,1$ become coefficients. But the sign there means either plus or minus, of plus moro things than 1. We have nothing more to do but to select any number we like between 10 and 30 , say 20,25, 30, and substitute it for the unknown quantity in the original equation. I take 20, and then find ont by taking firo times the first, of which I put only the first three figures, four times the second, three times the third; I then divide the difference between $f$ and $f 1$ by 950 , Thich gires mo $11,-$ (seo Ex. 4, pago 41).

But supposing I should make tho first digit 2, it does not mako any difference; the next would correct it. Then the second digit will be 3 by tho samo simplo process. But supposo I make it 4,5 , or 6 , it does not matter, the next step will always correct it. I continue that process, at last come to a stand-still. Now, I do not care whether I am right or wrong, I take ono decided step, and I find exnctly the value of $x$ to the serenth place of decimals, disregarding whether all that work is right, or whether it is wrong. I take for granted that I have assumed that to be the proper value of $x$. I square it, cubo it, take the fourth and fifth power of it, because wo cmploy the logarithm of the root. I immediately take tho original coefficients, sulistitute theso for the original coefficients, and no matter what has been dono beforo this, whether right or mrong in all that lias been done, I determine exactly the value of $x$; and $x$ is shorm to be equal to 20 times that dinal number.

$$
\therefore x=20 \downarrow 1,3,2,5,5,8,7,6=22 \cdot 7246716 .
$$

Norr, any mathematician that will undertake to find the ralue of 2 in that fifth power of the equation by any hnown process, I need not explain to many here the labour ho would have to go through. Sup5. 2 
posing I commenced my operations with 22 , I should get the dual number, $22 \mid 0,3,2,5,5,5,5,7$. That is the first I commenced with, simply because 2 is ensily raised to any power. Ifad I commenced with 15, I would have got the dual number, $15 ! 4,3,4,3,1,1,3,8$; had I commenced with 12 , I would have got the dual number, 12|6,6,6,9,8,4,4,7. I am not limited to what I should begin with. I am sure always to get the same dual logarithm, and the same common value of $x$ to the seventh decimal place.

In my larger work, when I enter into the limits of roots of equation, I show the shortest path. Although I show that the mere tyro cannot go astray, yet I also show how he can sare all his time by confining lis operations to the narrowest limits. In my works I then show how a dual number may alway's begin with a digit not higher than 3 ; that crery second dual digit may bo an 0 ; that it is not necessary to do anything but add or subtract, not to multiply by a digit higher than 5 .

If it were nothing but finding the roots of these common equations, $t$ would be of some use. But I undertake to solve the equation $x^{x}=u$, never solved before. I also solve $a^{x}+b^{x}=c^{x}$; an equation that Augruste Comte, in-his Philosophy of Mathematics, has stated that to solve this last equation has defied the will of mathematicinns, and that it mould be impossible to try to solve it.

I shall now go into the moro practical part of dual arithmetic.

The Cnarmsux: Would you explain one or two preliminary stages. Show the change of a natural number into a dual number, and a dual number into a dual logarithm and the reverse.

Mr. Brnes: Very well. I will put in the first position any digit you like. I will put down the arrow and the digits.

$$
\begin{gathered}
\downarrow 3,4,5,7,6,2,5,8, \\
\frac{13,4,5,7,6,2,5,8,}{1520250}=8,0+, 05,0 \times \div \% \\
33056008
\end{gathered}
$$

The first three digits multiplied by 5, with 0 after each which subtract. I have only two more numbers to operate with to reduce a dual number to a dual logarithm. I will put them down, 31018 and 33.

$$
\begin{aligned}
& 33056008 \\
& 03054=\text { First digit times } 31018
\end{aligned}
$$

$$
\begin{gathered}
\overline{33149194}= \\
\text { Dual logarithm of } \downarrow 3,4,5,7,6,2,5,8 \text {. }
\end{gathered}
$$

That is a dual logarithm. Any schoolboy would acquire the rule in five minutes. The reversing of this process would bring $a$ dual logarithm back to a dual number, a process which never conld be done before. It was possible to calculato a logarithm with great labour, lut to get a number back again was quito a different matter. I will 
put down nuother dual number, composed of both ascending and deseending bianches.

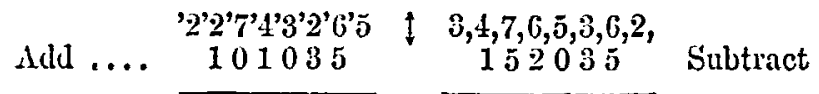

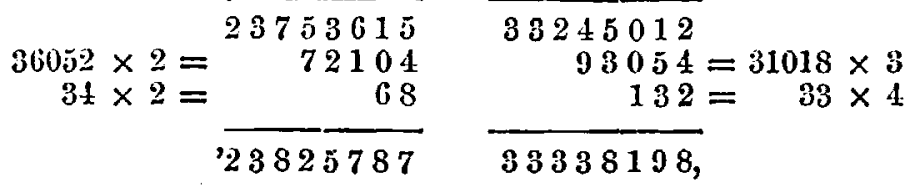

Stuposing I wish to reduce a dunl num ver composed of twc branches to a dual logarithm at one and the same time, the differcuce of these numbers liave to be taken:

$$
\frac{\begin{array}{r}
33338198, \\
23825787
\end{array}}{9512411}
$$

The constants employed for the descending branch are 36052 and 34.

Taking it for granted, therefoie, that the operator can convert natural numbers into dual numbers, dual numbers into dual logarithms, and the reverse, it is, indeed, a kind of gymnastics in calculation very casily acquired. IIe, then, has to recollect that the arrow tells the position in which the first digit stands. Thus $\prod^{3} 3$ indicates that the second 3 is in the third position; but as there is no figure on the arrow thus written

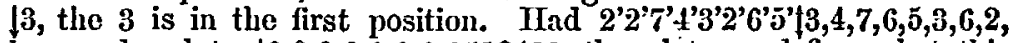
been reduced to $10,0,0,0,0,0,0,9512411$, then let me define what this dual logarithm is ; that the dual number corresponding to it would be an 0 in the first position, an 0 in the second, an 0 in the third, an 0 in the fourth, an 0 in the fifth, an 0 in the sixth, and 0 in the seventh position; and the dual logarithm in the eighth position is 9512411, if I put 9512411, in the eighth position, we have a dual logarithm when all the other digits are zeros, which is nothing more than the baso 1.00000001 raised to the power 9512411. All dual logarithms are whole numbers; there are no fractions. Therefore; 1.00000001 is the base that-I have selected, and is much more correct thau logarithms to seren places of figures, and is true to the singlo digit in the eighth placo; altogether true to seven places.

But a common logarithm is this: 10 being the base raised to the powrer of $\cdot 30103$ is nearly. cqual to 2 ; 10 raised to the power of 0.0103 a decimal, -30103 called the logarithm of 2 . That is the common logarithm of 2 . The base of a common logarithm being 10 , tho power to which 10 is to be raised to produce 2, that power is termed the common logarithm of 2. The hyperbolic system of logarithms are employed in the differential and integral calculus, and is of this sort:- 
raised to the power of $\cdot 09314718=2$. It lappens that the dual logarithm of a number and the hyperbolic lognithm tice made up of the same figures; but onc of them is divided by 100000000 . So when I hare the dual logarithm of a number I hare only to cast off 00000000 , eight decimals on the right, and I have the hyperbolic logarithm. The dual logarithm, therefore, answers all scientific purposes without any transmutation or change, while it has to be changed in other systems; $(1 \cdot 00000001)^{: 9314718}=2$. If we take $2 \cdot 718281828$ for a baso it is very. awkward. Now, to compare my base with $2 \cdot 718281828$. If I require greater accuracy, I take 1.000000001, the base beyond 1.00000001; if I require greater still $I$ tako the base beyond $1 \cdot 000000001$. If I want a calculation true to 20 places of figures, I take 100000000000000000001 , which 5ou will see explained in my book. But there is no way in which you can change a fixed number like 10, or $2 \cdot 718281828$; my base will give it the power of a series of bases, and so the flexibility of a dual number is of great advantage in many ways.

I lave taken the Nautical Almanac for 1836, and the plan of calculating longitudes by eclipses or transits. It is necessary first to ascertain the radius of the place where I stand, also the longitude of the place where I stand, together with the latitude of it. In this work the expression for the radius p;-Ex. 7, page 46. That is $\rho=\left(\frac{\cos l^{\prime}}{\cos l\left(\cos l^{\prime}-2\right)}\right)^{\frac{1}{2}} ; \cos l$ is the cosine of the centre latitude; the other $l^{\prime}$ is the greater latitude, that given by the line perpendicular to the horizon. Now, to find the value of that expression, I give a simple rule, page 10, which is nothing more than to divide double the cosine by 3; multiply that by $1000^{\circ}$ and the dual number $\downarrow 0,1,6,0,1,0,2,0$, and the result gives the seconds. I need only go as far as 60.1, having only used the first and second dual numbers; and I find the number of dual seconds to be 614, consequently the two latitudes differ by 614". Such a calculation as that is very easily made by dual arithmetic. Now, the cosino of $l^{\prime}$ is rery nearly equal to the cosine of $l$. The details of the solution of this problem is given at pp. 10, 11. If you observe, the cosine of $l^{\prime}$ is so very near the cosine of $l$, you can tell by a few additions and a few subtractions that that is the dual logarithm of the cosine of $n$, and nearly the cosine of 1 . I can tell tha difference at once betreen the dual log cosines of these two latitudes.

Sir Jons Har: You say a few subtractions. Will you point out the subtractions.

MIr. BYRNE: I hare to do something with the number $\cdot 84362800$ until it becomes equal to 86502350 , Ex. 7 . If you observe, I add twice to it in periods of three figures. Thus-

$$
\begin{array}{r}
8 \pm 362800 \\
1 \mid 686 \\
866
\end{array}
$$

Sir Jorr $\Pi$ Ir: You multiply the first three figures.

Mr. Brene : Yes, that is by $1,2,1$, for 2 . That number differs from the original number, reference being made to the numbers 
.81502350

.84511570

(Sce page 46.)

9220 difference

Common division gives the remaining numbers, but they are obviously on the descending side. "These are all found by subtractions, and only one by addition. That, then, is the dual number, which represeuts at once a dual logarithm. I do not want to retrace my steps. I would have been approximating towards these results lad I to turn back. Now I wish to find the radius of the earth in the proposed jatitude. There is the dual logarithm '1885991, page 47, already found. Divide by 2 for the square root. I have reduced my formula into the logarithm of the difference of the cosines. When I havo grot the cosine I divide that, and find the common number. By dividing the dual number by the logarithm of 10 , there is the common logarithm of $\rho$, see page 47. In one minute I find the common logarithm of $p$, an operation which gives astronomers a great deal of trouble; bccauso I bring the logarithm back to the dual number. The length of

\section{$\rho$ is $\cdot 99905768$}

Supposing it is necessary to obtain this with greater accuracy. It is no matter, if you want a liundred places of figures it is all the same, without employing any extraneous number. Now I take a more extensive number than that. Ilere is a problem (Example 8, page 47) tuat lias engaged the attention of naval men for a long time, that of datermining the longitude at sea by lunar observations. The solution of this question called the Nautical Almanac into existence, and, I believe, a large book-case might be filled with works on this problem. I will show how to solvo it without any logarithm whatever, without a table, without any operation except the operations exhibited in Ex. 8 and Ex. 5.

The Cindmusax: The additions and subtractions alluded to are explained in this little book.

'The liev. Waxter MItrcheld : Iraving been a pupil of MIr. Byrne, I think I know what the gentlemen present wish to have explained. Perhaps it would be interesting to them to see how readily a knowledge of Mr. Byrne's method may be acquired.

There are two branches of Mir. Byrne's art, an ascending and a descending: You may work with either alone, or save a considerable amount of arithmetical computation by combining the two. For the sake of simplicity I shall confiue my attention to the ascending branch, aud show with what ease any dual number of that branch can be converted into a common number, and conversely, how any common number can be changed into a dual one.

I will write down a dual number-

$$
17,2,6,0,7
$$

The arrow -1 is a sign that the numbers following it represent a dual 
number of the ascending branch, and not a common number. The figures 7,2,6,0, \&c., following the arrow, are called dual digits, cach digit being separated by a comma, these digits may be any number greater or less than 10. The digits again are said to be in tho 1st, 2nd, 3rd, or 4th position, according as they stand in the 1st, 2nd, 3rd, or 4 th position to the right of the arrow.

This number $\downarrow 7,2,6,0,7$, is a contracted representation of the continued product.

$$
(1 \cdot 1)^{7}(1 \cdot 01)^{2}(1 \cdot 001)^{6}(1 \cdot 0001)^{n}(1 \cdot 00001)^{7}
$$

The first practical value of the dual arithmetic which we may notice, depends upon the case with which any number may be multiplied by any of tho powers of numbers of the form 1.1, 1.01, $1 \cdot 001$, sic.

'Thus, according to our notation,

$$
\begin{aligned}
& \downarrow 1,=1 \cdot 1=1 \cdot 1 \\
& \downarrow 2,=(1.1)^{2}=\frac{11}{1 \cdot 21} \\
& \downarrow 3,=(1 \cdot 1)^{3}=\frac{121}{1 \cdot 331} \\
& \downarrow 4,=(1 \cdot 1)^{4}=\frac{1331}{1 \cdot 4641} \\
& \downarrow 5,=(1 \cdot 1)^{5}=\frac{1 \cdot 1611}{1 \cdot 61051} \\
& \downarrow 6,=(1 \cdot 1)^{6}=\frac{161051}{1 \cdot 771561} \\
& \downarrow 7,=(1 \cdot 1)^{7}=\frac{1771561}{1 \cdot 9487171} \\
& \downarrow 8,=(1 \cdot 1)^{8}=\frac{19487171}{2 \cdot 14358881} \\
& \downarrow 0,=(1 \cdot 1)^{3}=\frac{214358881}{2 \cdot 357947691}
\end{aligned}
$$

In the abore example it will bo readily seen, that we have obtained the first nine dual digits in the 1st position, or, in other words, the first nine powers of $1.1 \mathrm{by}$ simple addition.

This method of multiplying by dual digits, using simple addition, may be thus generalised. Suppose we multiply the number $3 \cdot 14159$ loy $\mid 0,0,1$, or the dual digit 1 in the third position, which stands for the number $1 \cdot 001$.

Now by common multiplication- 


$\begin{array}{r}\begin{array}{r}3 \cdot 14159 \\ 1 \cdot 001\end{array} \\ \hline 314159 \\ \mathbf{3 1 4 1 5 9} \\ \hline 3 \cdot 14473150\end{array}$

But this multiplication can easily be performed by addition in two lines, by simply repeating the number to bo added, placing its cligits in the second line three figures to the right, thus-

$$
\begin{aligned}
& 3 \cdot 141159 \\
& 31.11 \% 0 \\
& \overline{3 \cdot 14473159}=3 \cdot 14159 \times 10,0,1
\end{aligned}
$$

'This process can casily be expressed in general terms, thus-'l'o multiply any number by a dual digit 1 , in any position write the number under itself, placing its digits as many figures to the right as the number of the position of the dual digit. This very casy rule will enable us at once to determine the common number which corresponds to the dual number $\downarrow 7,2,6,0,7$. 'To aroid needless figures we shall only carry ont our result to eight places of decimals, we have already found the value of $\downarrow 7$ to be $1 \cdot 9487171$.

$$
\begin{aligned}
& \left.1 \cdot 9\right|_{19 \pm 8717} ^{487171}=\sqrt{7}, \\
& 1 \cdot 96820427=\mid 7,1, \\
& 1968204 \\
& 1 \cdot 98788631=17,2, \\
& \begin{array}{c|c}
\frac{198789}{987420} \\
198987
\end{array}=17,2,1 \text {, }
\end{aligned}
$$

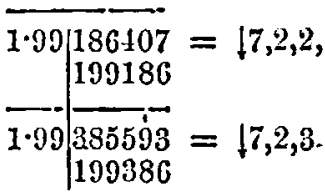

$$
\begin{aligned}
& 1 \cdot 99584979=17,2,4, \\
& 190585 \\
& 1 \cdot 09 \mid 784564=17,2,5, \\
& 199785 \\
& 1.999841349=17,2,6, \\
& 12000
\end{aligned}
$$




$$
\begin{aligned}
& 1 \cdot 9998 \underset{2000}{6349}=\mid 7,2,6,0,1, \\
& { }^{1 \cdot 9998}\left\{\begin{array}{l}
8349 \\
2000
\end{array}=\sqrt{7}, 2,6,0,2,\right. \\
& 1 \cdot 9999 \mid \begin{array}{l}
0349 \\
2000
\end{array}=\sqrt{ } 7,2,6,0,3, \\
& 1 \cdot 0999\left[\begin{array}{l}
2349 \\
2000
\end{array}=\sqrt{7}, 2,6,0,4,\right.
\end{aligned}
$$

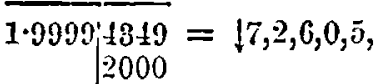

$$
\begin{aligned}
& \overline{1 \cdot 9999} \sqrt{63 \pm 9}=17,2,6,0,6, \\
& 1 \cdot 999983 \pm 9=\downarrow 7,2,6,0,7,
\end{aligned}
$$

According to the rules of decimal arithmetic, if we neglect any number in the 9th place, we make the number preceding it greater by one if the neglected digit be greater than 4.

The same method may eridently be extended to a dual number of any number of digits.

It must not be supposed that this is the only or most expeditions method of conrerting a dual number into a common number, I only use it to show that this conversion can be made by simple addition without

uming any law of binomial coefficients, or any arithmetical process but that of simple aldition.

I shall now show, conversely, how to find the dual number corresponding to a common number. Suppose we require the dual number which represents the number $1 \cdot 123 \pm 7036$.

Referring back to our list of the values of the first nine dual digits, we see that our number must be between $\downarrow 1$, and $\downarrow 2$, or we might make our table till our first two digits corresponded with the number

$$
\begin{aligned}
& \left.1 \cdot 1\right|_{11}=11, \\
& \frac{\left.1 \cdot 1\right|_{11} ^{11}}{111}=11,1, \\
& 1 \cdot 12211=11,2,
\end{aligned}
$$

Now, it is evident if we increase the second dual digit by 1 , our new number will become too great, we therefore proceed to the third digit:- 
Any increase of the third digit will make the number too great, we therefore proceed to the fourth and following digits :-

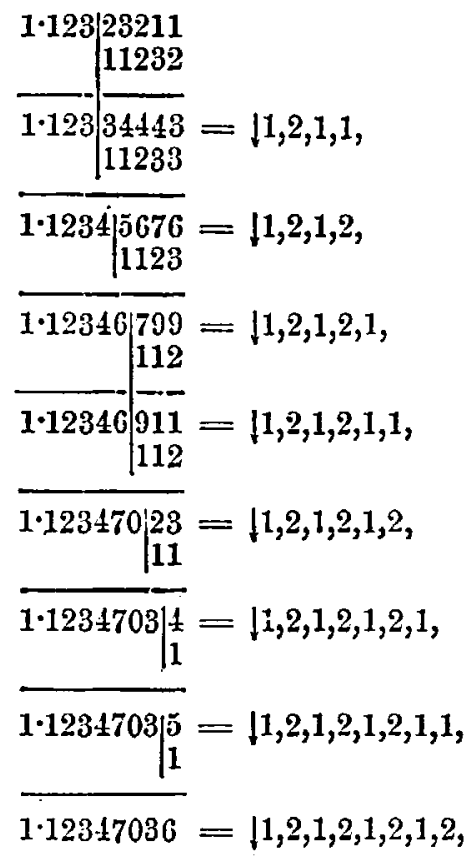

I havo thus shown how any common number can bo reduced to a dual number, and conversely how any dual number can bo changed into a common number by simple giddition. Now, the next thing I propose to do is to convert a dual number into a dual logarithm. Here I may notico a very curious fact. Any common number may be represented by a vast number of dual numbers, each differing from each other as to their digits, but all, when reduced, producing the same common number. For instance, the dual number $\$ 7,2,6,0,7,8,2,6$, may be represented by another dual number, whose first digit is zero, and its third digit some number greater than 70. This may again be reduced to another whose second digit is also zero; and so on wo may reduce the original dual number into one whose first seren digits are zero's, and its eighth digit some large number. I cannot detain you by demonstrating the method of this reduction, but shall content myself by stating how it may be done by a simple arithmetical rule. Write the dual number as a common number; add to this the number 31018 multiplied by the first digit, and 33 multiplied bo the second digit; subtract from this sum five times the first three digits, each followed by zero, written as a common number.

Thus to find the dual logarithm of the dual number- 


$$
\begin{gathered}
\begin{aligned}
& 17,2,6,0,7,8,2,6 \\
& 217126=7 \times 31018 \\
& 66=2 \times 33 \\
& \\
& 72825018=702060 \times 5 \\
&-3510300=79314718
\end{aligned} \\
\text { or, } 17,2,6,0,7,8,2,6=10,0,0,0,0,0,0,69314718
\end{gathered}
$$

which also means that the number $\left(1+\frac{1}{10^{9}}\right)$ raised to the power indicated by the whole number 69314718 will produce the common number represented by the dual number $\downarrow 7,2,6,0,7,8,2,6$, which by the metlind of reduction I have already demonstrated cau be shown to be equivalent to the common number 2.

Wre, therefore, call the number 69314718 the dual logarithm of the number 2.

Now, I think I hare succeeded in showing jou low the dual logarithm of any common number nay be obtained. These clual logaritlms possess all the porrers and properties of any other logarithms, and are in addition available for operations in which common logarithms would fail. Besiles the hyperbolic or Napierian lognrithms, and the Briggs' or. common logarithms can at once be calculated from them.

To convert a dual logarithm into a hyperbolic one count off cight figures and place a decimal point.

Thus-69314718 is the dual logaritlm of 2.

-69314718 is the hyperbolic logarithm of 2 .

230258509 is the dual logarithin of 10 .

$2 \cdot 30258509$ is the hyperbolic lognithin of 10 .

To convert a dual logarithm into a common logarithm, that is, one whose base is 10 ; all we have to do is to divide the dual logarithm by. the number 230258509 , which is the dual logarithm of 10 , which can readily be done by the rule for contracted division by decinals.

If our number be greater than 2 it is crident that our first dual digit will bo greater than 7 , but if our number be greater than 2 by dividiing it by $2_{2} 4$, or 8 , and some power of 10 , we can always reduce it to a number of the form of a decimal whose first digit does not exceed 1 , and is followed by the decimal point.

Now, if Professor Byrne had taught nothing more than what I lave now shown you that $I$, as his pupil, can do, and any of you can do for yourselves by the simplest arithmetical processes, he would have a just right to claim the merit of doing what all his predecessors, as mathematical professors, have failed to do, from the days of Napier, Briggs, and Newtoin, to the present time. But, in addition to this very clementary part of his art, MIr. Byme has shown you the application of it to the solution of questions of vast importance, hitherto defying the power of the calculator.

Mrr. Brnxe: I feel very proud of my pupil, and I think he has dono it a great deal better than I could do it myself. But had I to stop here, 
and could I only have shown you what lias been discussed in this lecture I would not have made my appearance here. But I have satisfied myself that, in the five rolumes already printed, of . which you will find on this table an account, I have framed a system to supersede mathematics as it is by the iutroduction of a new science called the Calculus of Form, out of which the dual calculus has gromn. The books which I have in the press will supersede the differential and integral calcultus, and clear awny fallacies upon which they are based.

The Cnamsrax: We hare had an cxtraordinary lecture. It evidences extreme boldness if it is untrue, and if it is true, it has extreme ingenuity, when we remember that any extension of the powers of analysis under the old systems, las but increased the difficulty and mystification, for it was no uncommon thing for mathematicians not to be able to read their own answers. Now, this system is really very simple. I have myself gone through a great deal of this little book, and the operations are as simple ns those that have been exhibited to you by Mr. Nitchell; in fact some of the process exhibited by Mr. Byme, and which seemed so very difficult, are merely an application of the simple process explained by Mr. Mitchell. It is a subject so important that it ought to be investigated. (IIfear hear). Mr. Byrne has thrown down the gauntlet, and such immense consequences in every department of mathematical science are involved, that the system ought to be fully tested. If any gentleman has any objection to offer, he ought to come forward and substantiate that objection, if not, he ought to admit the system to be correct. It males mathematical investigations possible to the million. The system is easy to be comprehended by the lowest intelligence; it is just as simple as any of the operations of common arithmetic, and less abstruse and difficult than some. There are a thousand occasions which occur to us when we should like to be independent of the actuary, the mathematician, and the naral architect. We professional men would like to be alble to calculate for ourselves, and the fact of our professional knowledge would give us powers of analysis, or means of addressing oursclves to obtain results that we liave not now, because mathematicians in looking at things from their awn stand-point and not from ours, do not really arrive at the result we want-I mean the practical result. Now, this system will render crery man independent of the actuary and the mathematician in every direction. I beg gentlemen not to be dismayed because there is a new system of notation which seems difficult, but which is not really so. But though new it is rery simple and definite, and enables you much better to keep in view your clanse. $\Lambda$ little attention to it, throwing overboard what you have been indoctrinated with to a great extent, and beginning as it were with a blank shect, yon will find it simple, and, ns you go on, you will be astonished at the immense power which you will find in your hands. I beg to commend it to this assembly. Wo have to thank not only $\mathrm{Mr}$. Byrne for the invention of it and for bringing it forward, but also $\mathrm{Mrr}$. Mitehell for the rery lucid way in which he has illustrated it. We have also to thank- 
Messrs. Bell and Daldy for the public spirit with which they hare taken up this scheme. Without any immediate prospect of results, disregarding rested interests, they hare invested a considerablo sum of moncy in its publication. I contend that they are national benefactors. The Council will be anxious to afford every facility for inrestigation, and no doubt would give a meeting for the purpose, when questions might be asked; and to facilitate the matter some of the questions should bo pnt in mriting. Mrr. Byrne ias been soaring in the highest regions of mathematics until he has got quite transcendental. We unfledged ones must try to bring: him down to us till we are able to fly.

Rear-Adniral Sir Frederick Nicossox, Bart., C.B.: Mrr. Byrne has stated that his system will supersede the integral and the differential calculus.

The Crarrunas: Practically it comes to that, it is more accurate and much more simple in its determinations; and, as he stated to you in one or two cases, which might be multiplied indefinitely, there are equations which cannot be worked ont by any other method; therefore, as far as that goes, the other systems are valueless.

Sir Fredenick Nrcotsox: I simply wanted to put a question. As far as I understand the question it is an easier way of solving problems, which have hitherto been solred by the differential and integral calculus. That is as I understood it. At any rate, it is quite a norel proposal in mathematics. Mr. Byrne has giren great attention and great labour to it, and has published elaborate books on the subject. The question I was going to ask was simply this, whether these calculations and these books hare been submitted to any mathematician of well-known capacity, in order to gire a deliberato and an independent opinion on them?

Mr. Scotr Russezl: Perhaps you will allow me to answer that question. I say that. Mr. Mitchell is himself one of the highest mathematicians in the land. I beliere the subject came before him, not as a pupil, but as a judge; and I believe the consequence of its so coming before him as a judge, was that he entered himself as a pupil.

Tho Rer. TV Alter MIrchels: I wili endenvour to answer Sir F. Nicolson's question. The whole of the dual arithmetic, and all tho works now passing through the press, and all the tables, I havo looked through myself, and I have not found a faulty demonstration. Every problem is worked out by methods and principles as simple and as casy as anything I haro shown you; and that, I think, must be saying something about things which belong to transcendental analysis, and therefore litherto only to be understood by those who can enter into the highest branches of mathematical science. If this be true, it is something to have the most abstruse speculations the human mind can enter into, reduced to simple addition and subtraction. In MIr. Byrne's book you will find problems solred by the aid of La Place's theorem, and by the nid of La Grange's, and you will find the highest methods of the differcntial calculus leading you to equations of most difficult solution, and you will bo inclined to say, "What a rery awkward system this is in obtaining the truth." 
Then you hare these same problems solved by processes ns simple as those I have shown you. But Mr. Byrne goes further, and gets simple solutions of problems where the theorems of Ia Place and. La Grange and all other known methods, utterly fail to give any result.

The Grramurax: Haring worked out the results by Mrr. Byme's method, any one can establish by existing means that the answers are perfectly triue. I repeat that it is perfectly within the compass of any one hero present, to establish that the answers are true. The Council will be glad to give the mecting an opportunity to ask questious.

Adjourned to Wednesday erening, January 24 th.

\section{Adjounsted Miefing.}

TVednesday, January 24th, 1866.

\section{Rear-Adimat Sir F. E. NICOLSON, Bart, C.B., in the Chair.}

The Cnarrurav : Tre are about to resume the discussion of Mrr. Byme's .paper, which was read the other day. I believe MIr. Byrne wishes to make some additional statements.

Mr. Brrye: Viewing this subject from different stand-points, I rapidly passed over one development after another without entering upon minor details. It is rery important at starting upon any subject that we start right; therefore, I left it for a separate explanation, and I lare taken three examples, the solutions of which are exhibited on the black board. All the figures employed are set donn. Although they are common place questions they could not be.done without great labour before I discorered this art and science. I have not taken the casiest plan, because that would not bring with it the method of inrestigating, and you will find that that method of teaching which approaches the method of inrestigating most nearly is always the best.

The numbers exhibited in the tabulated form I call operatire numbers. They are used sometimes as binomial coefficients; they are employed in the calculus of differences; and found useful in calculations respecting the doctrine of chances. This tabulated form is sometimes called the arithmetical triangle. I use it in three lifferent ways. When I employ these numbers in one way in raising a power, it differs materially in the use of them, in passing from step to step, whether positive or negatire. Any one can form this table in a minute or so. I set down a line of one's perpendicularly, and one horizontally. I commence with a line of units in a horizontal direction, and another line in a perpendicular direction. 